AWARD No. : $\quad$ DE - FG 07 - 02ER63222

AWARDEE NAME: Florida State University

ACCOUNT No.: $\quad$ EMSP 73749

PROJECT TITLE: Chemical Speciation of Strontium, Americium, and Curium in High Level Waste: Predictive Modeling of Phase Partitioning During

Tank Processing

PERIOD COVERED: Annual Report, 6/1/02 - 5/31/03

P.I.: $\quad$ GREGORY R. CHOPPIN 


\section{Annual Report 2003}

\section{Chemical Speciation of Strontium, Americium, and Curium in High Level Waste: Predictive Modeling of Phase Partitioning During Tank Processing}

\section{Research Objective:}

The objective of this research project is to measure the effects of organic chelate complexation on the speciation and solubility of $\mathrm{Sr}$ and trivalent actinides under strongly basic, high carbonate conditions, similar to those present in high- level waste tanks at U.S. Department of Energy storage sites. We proposed, (1) extension to important chelates not previously studied; (2) studies of completing metal ions; and (3) specific studies using Am(III)/Cm(III). The chelate complexation studies would extend our previous research on EDTA, HEDTA, NTA, and IDA to citrate and oxalate. In addition, we propose to address the possible formation of mixed ligand-ligand complexes for Eu(III) in EDTA-HEDTA, EDTA-NTA, HEDTA-NTA, and ligand-carbonate solutions. The fundamental data on chemical speciation and solubility will be used to develop accurate thermodynamic models which are valid to high ionic strength.

\section{Research Progress and Implications:}

This report summarizes work after the first year of a 3 year project.

For the safest and most economical management of the large volumes of high level waste (HLW) in tanks at DOE sites, studies on speciation of the important longlived nuclides such as ${ }^{90} \mathrm{Sr}$, and trivalent actinides ${ }^{241} \mathrm{Am},{ }^{244} \mathrm{Cm}$ and also Eu are necessary. At present, $\log \beta_{1}$ values for the complexation of Eu with citrate ion and ${ }^{241} \mathrm{Am}$ with EDTA at different temperatures ranging between 0 to $60^{\circ} \mathrm{C}$, along with the changes in enthalpy and entropy for these complexes have been initiated. This is part of the program of the research to be done at the Florida State University, Department of Chemistry.

Solvent extraction technique employing HDEHP as the extractant has been utilized in the work. The $\log \beta_{1}$ values for the formation of the $1: 1$ complex of $\mathrm{M}^{3+}$ - 
citrate or -EDTA anion in $5.0 \mathrm{M} \mathrm{NaClO}_{4}$ and the related $\Delta \mathrm{H}$ and $\Delta \mathrm{S}$ values are being measured using standard methods.

The hydrogen ion molarity in $5.0 \mathrm{M} \mathrm{NaClO}_{4}$ was determined using the equation $\mathrm{pcH}=0.8481 \mathrm{pHr}+1.5144$. The free citrate ion concentration $\left(\mathrm{cit}^{3-}\right)$ was evaluated using the literature data of $\mathrm{pKa}$ values of citric acid in $5.0 \mathrm{M} \mathrm{NaClO}_{4}$.

Figure 1 gives the plot of $\left[\mathrm{Cit}^{3-}\right]$ vs. D0/D- 1 for the $\mathrm{Eu}^{3+}$ system at temperatures 0 , 25,45 and $60^{\circ} \mathrm{C}$. From the slope of such straight lines the $\log \beta_{1}$ values were evaluated and are given in Table 1 . The thermodynamic parameters at $25^{\circ} \mathrm{C}$ were evaluated as $\Delta \mathrm{G}=$ $-31.95 \mathrm{~kJ} / \mathrm{mole}, \Delta \mathrm{H}=22.4 \mathrm{~kJ} / \mathrm{mole}$ and $\Delta \mathrm{S}=182 \mathrm{~J} / \mathrm{mole} . \mathrm{K}$.

Work on ${ }^{241} \mathrm{Am}$ with EDTA at $5.0 \mathrm{M} \mathrm{NaClO}_{4}$ under the conditions reported above, has been started, and has been completed for the temperatures 0 and $25^{\circ} \mathrm{C}$. The work at 45 and $60^{\circ} \mathrm{C}$ is in progress. This will give, for the first time, thermodynamic parameters at very high ionic strengths for the trivalent actinide - EDTA systems.

\section{Planned Activities:}

The future activities of this project over the next 12-months will include a study of EDTA complexing of $\mathrm{Cm}$ and Eu and of citrate complexing of $\mathrm{Am}$ and $\mathrm{Cm}$ at $5.0 \mathrm{M}$ $\mathrm{NaClO}_{4}$ and temperatures up to $60^{\circ} \mathrm{C}$.

It is also planned to complete the complexation study of Am with citrate and Eu with EDTA and then to start work on the mixture of citrate and EDTA with Eu and Am. The work with $\mathrm{Cm}$ will proceed after finishing the above work since it is expected that the behavior of Am and $\mathrm{Cm}$ is going to be very similar.

The spectroscopic measurements with $\mathrm{Eu}$ and $\mathrm{Cm}$, especially with the mixture of citrate and EDTA, will be of great importance and relevance in deciding the number of coordination sites of these metal ions occupied by the above ligands and $\mathrm{H}_{2} \mathrm{O}$ molecules. This will be of value in deciding whether the higher solubilities of trivalent actinides and lanthanides, as observed with the simulants, are due to the formation of mixed complexes of the organic ligands or is due to some other factors which must be determined. 
Table 1: Stability constant and thermodynamic parameters of $\mathrm{Eu}$ - citrate system in 5M $\mathrm{NaClO}_{4}$

\begin{tabular}{|c|c|c|c|}
\hline \multicolumn{4}{|c|}{ A. Stability constant } \\
\hline \multicolumn{2}{|l|}{$\mathbf{T}\left[{ }^{0} \mathbf{C}\right]$} & \multicolumn{2}{|l|}{$\log \beta_{101}$} \\
\hline \multicolumn{2}{|c|}{0} & \multicolumn{2}{|l|}{$5.24 \pm 0.02$} \\
\hline \multicolumn{2}{|l|}{25} & \multicolumn{2}{|l|}{$5.60 \pm 0.02$} \\
\hline \multicolumn{2}{|l|}{45} & \multicolumn{2}{|l|}{$5.89 \pm 0.03$} \\
\hline \multicolumn{2}{|l|}{60} & \multicolumn{2}{|l|}{$5.99 \pm 0.02$} \\
\hline \multicolumn{4}{|c|}{ B. Thermodynamic values } \\
\hline$\Delta \mathbf{G}[\mathbf{k J} / \mathbf{m o l}]$ & \multicolumn{2}{|l|}{$\Delta \mathbf{H}[\mathbf{J} / \mathbf{m o l} . \mathbf{K}]$} & $\Delta \mathrm{S}[\mathrm{J} / \mathbf{m o l} . \mathbf{K}]$ \\
\hline-31.95 & \multicolumn{2}{|l|}{22.4} & 182 \\
\hline
\end{tabular}




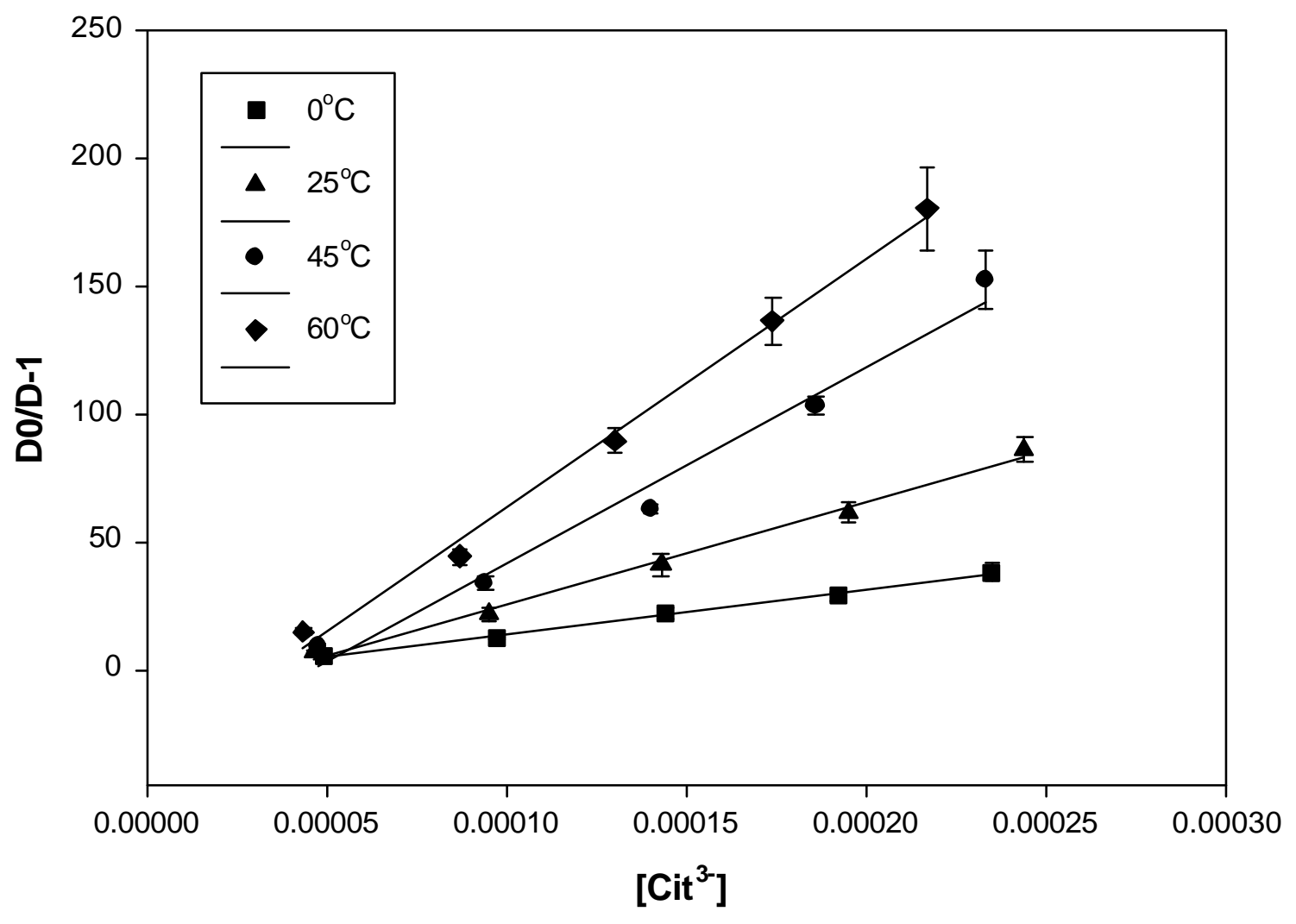

Fig. 1.: Plot of Do/D-1 vs. $\left[\mathrm{Cit}^{3}\right]$ at temperatures $0,25,45$ and $60^{\circ} \mathrm{C}$ 